\title{
Correction to: Mathematical modeling and experimental studies on axial drilling load for rotary ultrasonic drilling of $\mathrm{C} / \mathrm{SiC}$ composites
}

\section{Shafiul Islam ${ }^{1}$. Songmei Yuan ${ }^{1} \cdot$ Zhen $\mathrm{Li}^{1}$}

Published online: 23 June 2020

(C) Springer-Verlag London Ltd., part of Springer Nature 2020

Correction to: The International Journal of Advanced Manufacturing Technology https://doi.org/10.1007/s00170-020-05052-Z

\section{Correction 1}

Angle $\beta$ of Fig. 2 was inaccurately displayed in the initially published version. It has been accurately displayed in the updated version. The correct figure is:

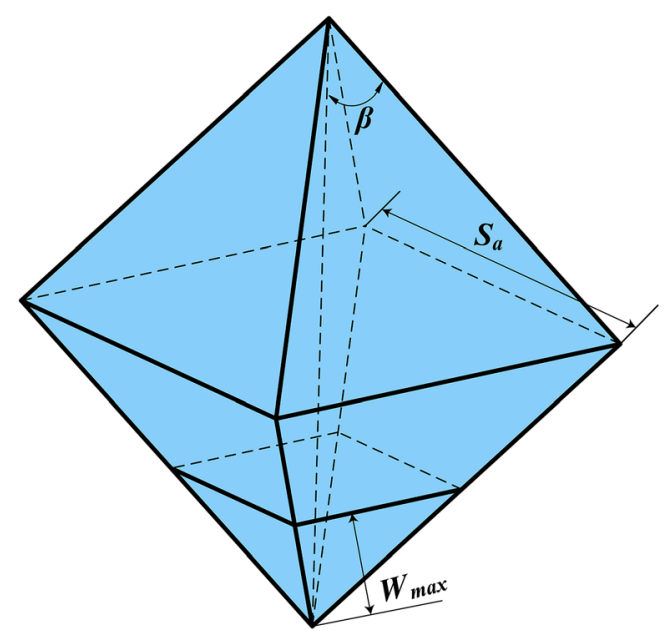

Fig. 2 Octahedron shaped diamond abrasive particle

The online version of the original article can be found at https://doi.org/ 10.1007/s00170-020-05052-z

Shafiul Islam

shafiul@buaa.edu.cn

$\triangle$ Songmei Yuan

yuansmbuaa@163.com

Beijing Engineering Technological Research Center of High-efficient \& Green CNC Machining Process and Equipment, School of Mechanical Engineering and Automation, Beihang University, Beijing 100191, China

\section{Correction 2}

There were slight mistakes in Eq. (8) and Eq. (26) of the initially published version. The equations have been corrected in the updated version. The correct equations are:

$$
\begin{aligned}
& \left\{\begin{array}{l}
w^{\prime}=w_{\text {max }}-(A \cos (2 \pi f t)+A) \\
t_{1}=\frac{\arccos \left(\frac{w_{\text {max }}}{A}-1\right)}{2 \pi f} \\
t_{2}=\frac{2 \pi-\arccos \left(\frac{w_{\text {max }}}{A}-1\right)}{2 \pi f}
\end{array} \quad t \in\left[t_{1}-t_{2}\right]\right. \\
& C_{L}=C_{2}\left(\frac{1}{\tan \beta}\right)^{\frac{5}{12}} \cdot\left[\frac{E^{\frac{3}{4}}}{H_{V} K_{I C}\left(1-\nu^{2}\right)^{\frac{1}{2}}}\right]^{\frac{1}{2}} \cdot F_{n}{ }^{\frac{5}{8}}
\end{aligned}
$$

\section{Correction 3}

One funding information was omitted in the initially published version. It has been added in the updated version.

Funding information This research was financially supported by the National Natural Science Foundation of China (Grant No. U1737201) and the National Science and Technology Major Project (Grant No. 2017-VII-0015-0111). The authors are indebted to these financial supports to accomplish this research work. 